\title{
Shrinkage stress and elastic modulus assessment of bulk-fill composites
}

\section{Abstract}

Fabio Antonio Piola RIZZANTE ${ }^{1}$

Rafael Francisco Lia MONDELLI ${ }^{2}$ iD

Adilson Yoshio FURUSE ${ }^{2}$

Ana Flávia Sanches BORGES²

Gustavo MENDONÇA ${ }^{3}$

Sérgio Kiyoshi ISHIKIRIAMA²
Submitted: March 28, 2018 Modification: July 3, 2018

Accepted: July 8, 2018
Bulk-fill composites were introduced in dentistry to accelerate clinical procedures while providing adequate outcomes. Concerns regarding the use of bigger composite increments rely on the polymerization shrinkage and shrinkage stress, which may generate gaps on the adhesive interface and result in a reduced success rate. Objective: To evaluate the polymerization shrinkage stress of different bulk-fill resin composites and their elastic modulus. Materials and Methods: Fourteen specimens were made for each of the nine different resin composites (seven with $12 \mathrm{~mm}^{3}$ and seven with $24 \mathrm{~mm}^{3}$ ): Surefill SDR flow (SDR), X-tra Base (XB), Filtek Bulk Fill Flowable (FBF), Filtek Z350XT Flow (Z3F); Tetric Evo Ceram Bulk Fill (TBF), X-tra Fil $(X F)$, Filtek Bulk Fill (FBP), Admira Xtra Fusion (ADM) and Filtek Z350 XT (Z3XT). Linear shrinkage stress was evaluated for $300 \mathrm{~s}$ with the aid of a linear shrinkage device adapted to a Universal Testing Machine. For each composite group, seven additional specimens $(2 \times 2 \times 25 \mathrm{~mm})$ were made and Young's modulus was evaluated with a 3-point bending device adapted in a Universal Testing Machine with $0.5 \mathrm{~mm} / \mathrm{min}$ crosshead speed and $50 \mathrm{KgF}$ loading cell. Results: For $12 \mathrm{~mm}^{3}$ specimens, three-way ANOVA showed that only SDR and TBF generated lower stress after $20 \mathrm{~s}$. Considering 300 $S, T B F, S D R$, and XF generated the lowest stress, followed by ADM, FBP, $X B$, and FBF, which were similar to Z3XT. Z3F generated the highest stress values for all time points. Considering $24 \mathrm{~mm}^{3}$ specimens after $20 \mathrm{~s}$, all bulk fill composites generated lower stress than Z3XT, except XB. After $300 \mathrm{~s}$, SDR, FBP, and ADM generated the lowest stress, followed by TBF and XF. For elastic modulus, one-way ANOVA showed that FBF, SDR, Z3F, and ADM presented the lowest values, followed by XB and TBF. FBP, Z3XT, and XF presented the highest elastic modulus among the evaluated composites. Conclusions: Bulk-fill resin composites presented equal to lower shrinkage stress generation when compared to conventional composites, especially when bigger increments were evaluated. Bulk-fill composites showed a wide range of elastic modulus values, but usually similar to "regular" composites.

Keywords: Resin composites. Polymerization stress.

${ }^{1}$ Case Western Reserve University, School of Dental Medicine, Department of Comprehensive Care, Cleveland, Ohio, USA.

2University of São Paulo, Faculdade de Odontologia de Bauru, Departamento de Dentística, Endodontia e Materiais Odontológicos, Bauru, São Paulo, Brazil.

${ }^{3}$ University of Michigan, School of Dentistry, Department of Biologic and Material Sciences - Division of Prosthodontics, Ann Arbor, Michigan, USA. 


\section{Introduction}

Despite advances in adhesive dentistry, resin composites still tend to fail in extensive posterior restorations due to wear, medium to long term adhesive interface deterioration, technical sensitivity, polymerization shrinkage and inadequate polymerization, particularly in class II restorations with cervical margins located in dentin or cementum. ${ }^{1-5}$ Defects on the adhesive interface are generated by the characteristics of resinous materials during the polymerization process. Composites generate shrinkage (polymerization shrinkage) that depends on the material composition and volume. ${ }^{5-10}$ Shrinkage can generate stresses that may lead to the formation of micro gaps and, thus resulting in microleakage of saliva and bacteria, adhesive interface degradation, secondary caries, pulpal changes, and consequently, clinical failure of the restoration. ${ }^{4,5,11}$

The incremental insertion technique is recommended to ensure a better marginal integrity because it reduces the development of polymerization shrinkage stress. ${ }^{12-14}$ However, despite the advantages of the incremental technique in ensuring a better polymerization and stress distribution, this technique is more laborious, technically sensible and timeconsuming. $8,10,15$

Bulk-fill resin composites are advised to be used in larger increments without compromising the degree of conversion (up to $4 \mathrm{~mm}$ according to some manufacturers). Concerns with the polymerization of large increments relies on the polymerization shrinkage and on the stresses generated in the tooth/ restoration interface. ${ }^{10,16-18}$ Promising results have been reported with these materials, mainly due to lower polymerization shrinkage, ${ }^{5,18,19}$ which also depends on the composite organic/inorganic matrix composition and properties such as viscosity and elastic modulus.

Although several materials with different viscosities and handling characteristics are commonly classified as bulk-fill resin composites, their properties can change considerably, especially due to modifications in the organic matrix, with the incorporation of monomers with higher molecular weight, as well as changes in filler content and incorporation of stress relievers. ${ }^{5,10,16,18,20-23}$

Composites can be subdivided according to their consistency in low- and high-viscosity. Higher shrinkage stress for flowable composites are expected since they generally have a higher organic content when compared to microhybrid and nanoparticulate composites, which can result in greater polymerization shrinkage and lower mechanical properties. ${ }^{22,24}$ Similarly, a lower Young's modulus may allow stress dissipation during the polymerization process, thus reducing the stress when bigger increments are used.25,26 Given this discussion, the viscoelastic behavior (and its development during the polymerization process) and the volumetric shrinkage are critical during the generation of polymerization stress, showing the importance of stress development among composites with different viscosities. ${ }^{25,26}$ The hypothesis of this study was that the properties of bulk-fill and regular composites would be different. Thus, the objective was to evaluate the polymerization shrinkage stress and the elastic modulus of different bulk-fill resin composites.

\section{Materials and methods}

This study evaluated nine different resin composites (Figure 1), having as response variables: linear shrinkage stress (considering two levels of specimen volume: $12 \mathrm{~mm}^{3}$ and $24 \mathrm{~mm}^{3}$ ), and Young's modulus.

\section{Linear shrinkage stress}

The tensile stress test was used to evaluate the linear polymerization stress of the composites. ${ }^{7,27}$ For this test, seven $12 \mathrm{~mm}^{3}$ and seven $24 \mathrm{~mm}^{3}$ specimens of each resin composite were used. The restorative materials were inserted between two metallic bases with $6 \times 2 \mathrm{~mm}$ surface dimensions (Figure 2). These bases were previously sandblasted (surfaces in contact with composites) with aluminum oxide, avoiding the need of applying an adhesive system. ${ }^{20}$

The metallic bases were adapted on a Universal Testing Machine (Instron model 3342, Instron, Norwood, MA, USA) by using an articulated arm connected to the $50 \mathrm{KgF}$ load cell (upper base), and by using a BENCOR multi testing device (lower base) (Figure 2). This ensemble was used to perform a real-time evaluation of the forces generated during polymerization for $300 \mathrm{~s}$.

To standardize the material volume, the resin composite was inserted between the bases, with $1 \mathrm{~mm}$ between them, resulting in a $12 \mathrm{~mm}^{3}$ constant volume and a $1.5 \mathrm{C}$-factor. The same test was repeated with 


\begin{tabular}{|c|c|c|c|}
\hline Group & Restorative material & Organic matrix composition & $\begin{array}{l}\text { Filler } \\
\text { weight (\%) }\end{array}$ \\
\hline ADM & Admira Xtra Fusion, VOCO, Cuxhaven, Germany & Ormocer resin & $84 \%$ \\
\hline FBP & Filtek Bulk Fill Posterior, 3M ESPE, St Paul, MN, USA & AUDMA, UDMA and 1, 12-dodecane-DMA & $76,50 \%$ \\
\hline FBF & Filtek Bulk Fill Flowable, 3M ESPE, St Paul, MN, USA & UDMA, BISGMA, Bis-EMA, Procrylat resin & $64,50 \%$ \\
\hline SDR & Surefil SDR flow, Caulk Dentsply, York, PA, USA & Modified UDMA, EBPADMA, TEGDMA & $68 \%$ \\
\hline TBF & $\begin{array}{c}\text { Tetric Evo Ceram Bulk Fill, Ivoclar Vivadent, Schaan, } \\
\text { Liechtenstein }\end{array}$ & Bis-GMA, UDMA & $78 \%$ \\
\hline $\mathrm{XB}$ & X-tra Base, VOCO, Cuxhaven, Germany & UDMA, Bis-EMA & $75 \%$ \\
\hline XF & X-tra Fil, Voco, Cuxhaven, Germany & Bis-GMA, UDMA, TEGDMA & $86 \%$ \\
\hline Z3F & Filtek Z350 flow, 3M ESPE, St Paul, MN, USA & Bis-GMA, Bis-EMA, TEGDMA & $65 \%$ \\
\hline Z3XT & Filtek Z350XT, 3M ESPE, St Paul, MN, USA & Bis-GMA, Bis-EMA, UDMA, TEGDMA & $82 \%$ \\
\hline
\end{tabular}

Figure 1- Different groups with respective composition and manufacturer

$2 \mathrm{~mm}$ between the bases, resulting in a volume of 24 $\mathrm{mm}^{3}$ and a reduced $0.75 \mathrm{C}$-factor due to the increase in the height between bases. Light curing was performed with $31 \mathrm{~J} / \mathrm{cm}^{2}$ radiant exposure. For this, samples were light-cured for $20 \mathrm{~s}$ over the $6 \mathrm{~mm}$ surface with a $1550 \mathrm{~mW} / \mathrm{cm}^{2}$ LED light-curing unit (LED Blue Star 3, Microdont, São Paulo, SP, Brazil). Irradiance was evaluated using a radiometer (RD-7, Ecel Indústria e Comércio Ltda, Ribeirão Preto, SP, Brazil) prior to the start of the experiment and after every 5 light activations to ensure the same conditions for every sample. The polymerization shrinkage induced stresses were analyzed by a specific software through the $50 \mathrm{Kgf}$ load cell deformation. Data was recorded as force (in Newtons) $\times$ time (in seconds) in graphs and converted to MPa by dividing the force results by the area of transversal section of the specimens $\left(12 \mathrm{~mm}^{2}\right)$.

\section{Young's modulus evaluations}

For Young's modulus test, a three-point bending test was used. Seven specimens of each resin were made through the insertion of the composite into a metallic matrix $\left(2 \times 2 \times 25 \mathrm{~mm}=100 \mathrm{~mm}^{3}\right.$ - ISO 4049) coated with a specific insulating gel (Gel tripla ação, KG Sorensen, Cotia, SP, Brazil).

The dimensions of specimens were standardized by positioning polyester strips (Kdent, Quimidrol, Joinvile, SC, Brazil) on both the upper and lower surfaces before light curing. The polymerization was performed on both the upper and bottom surfaces, in three points (left edge, right edge, and center), during $40 \mathrm{~s}$ for each one, according to ISO 4049 recommendations, for $240 \mathrm{~s}$ total and $372 \mathrm{~J} / \mathrm{cm}^{2}$.

The specimens were removed from the matrix and stored in distilled water at $37^{\circ} \mathrm{C}$ for 24 hours, in absence of light. Following, any excesses were removed

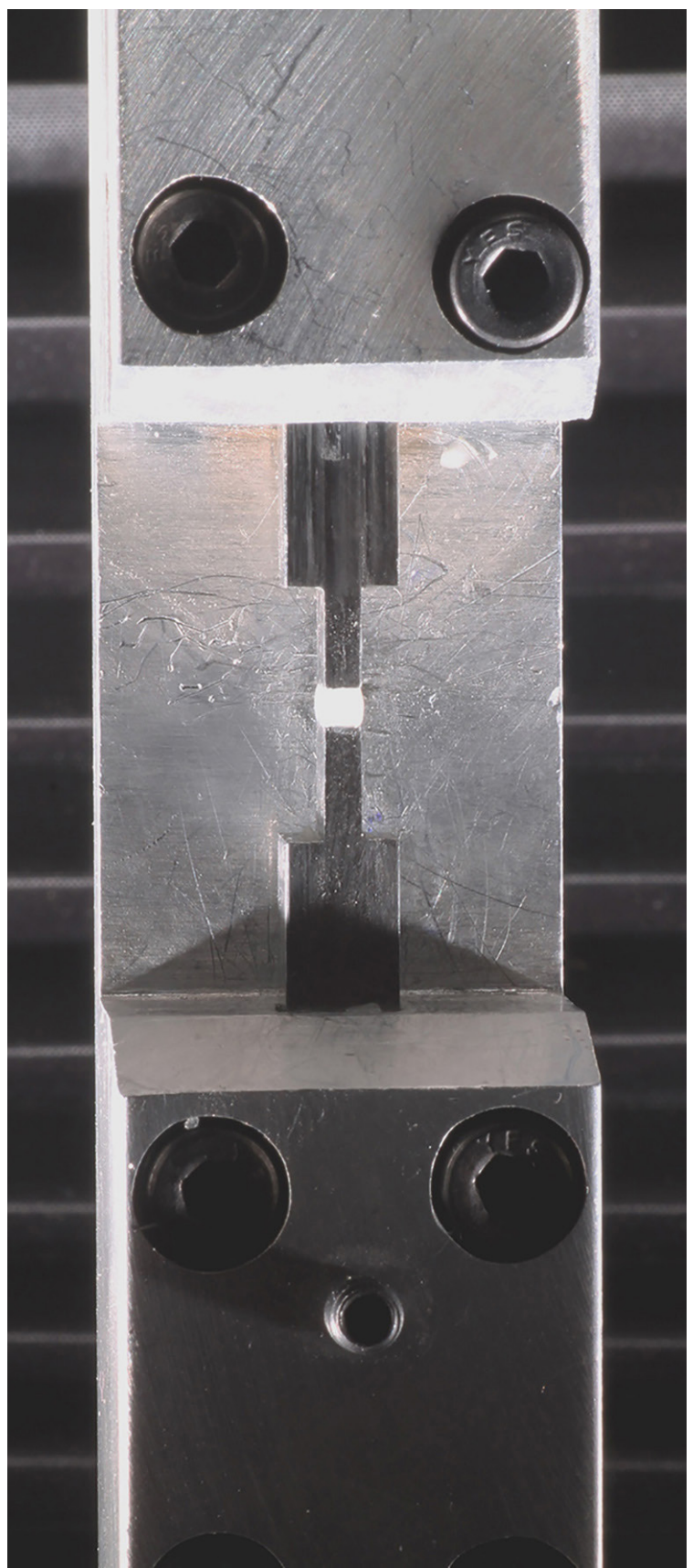

Figure 2- Universal Testing Machine (INSTRON) and metallic bases with composite specimen in position 
with a 1200 grit silicon carbide paper (Buehler Ltd., Lake Bluff, IL, USA) adapted in a polishing machine. The Universal Testing Machine was then used. The specimens were adapted in a flexural test device with 3 metal barrels. Two of these (separated by $20 \mathrm{~mm}$ ) were positioned on the bottom of the specimen. The third cylinder was positioned on the central upper surface, being responsible for the flexural stress. The force was applied through the superior articulated arm of the Universal Testing Machine at $0.5 \mathrm{~mm} / \mathrm{min}$ crosshead speed until specimen fracture. Elasticity young's modulus was determined through the onboard Instron software.

\section{Statistical analyses}

For all statistical analyses, 5\% was adopted as the significance level $(p<0.05)$. All data were evaluated for homogeneity through the Shapiro-Wilk test. For polymerization shrinkage stress, three-way ANOVA was used (time, composites and volume). For Young's modulus assessment, one-way ANOVA was used. All parametric tests mentioned above were followed by Tukey's test.

In addition, a linear regression analysis was performed considering Young's modulus and filler content, as well as considering Young's modulus and shrinkage stress.

\section{Results}

Table 1 describes the shrinkage stress tests with $12 \mathrm{~mm}^{3}$ and $24 \mathrm{~mm}^{3}$, the comparison between the different resin composites, as well as the values for Young's modulus.

Considering $12 \mathrm{~mm}^{3}$ (Table 1), after $20 \mathrm{~s}$, all bulkfill composites, except FBF and XB, were similar. Only SDR and TBF generated significantly lower stress when compared to the conventional Z3XT. After $300 \mathrm{~s}$, $\mathrm{TBF}, \mathrm{XF}$, and SDR generated the lowest stress values, followed by the other bulk-fill composites, which were similar to Z3XT. Z3F generated the highest stress values for all evaluated times.

Considering $24 \mathrm{~mm}^{3}$ specimens (Table 1 ), after 20 $\mathrm{s}$, all bulk-fill composites, except XB, generated lower stress values than Z3XT. After 300 s, SDR, FBP and $A D M$ generated the lowest stress values, followed by TBF and XF. Z3F generated the highest stress for all evaluated times.

After the volume increase, only ADM, FBP, and SDR generated similar values (20 s), regardless of the material volume (Table 1). After 300 s, SDR and FBP presented similar values regarding the different increment volumes.

Figure 3 shows the development of the shrinkage stress for the different composites. All bulk-fill composites showed smaller vertical lines when compared to their regular counterparts (Z3XT or Z3F). ADM showed the smallest vertical line, meaning that stress generation was slower.

Considering Young's modulus, the flowable composites (FBF, Z3F, SDR, and XB) presented the

Table 1- Shrinkage stress (in MPa) for 12 and $24 \mathrm{~mm}^{3}$ increments, and Young's modulus (GPa) - Mean (standard deviation)

\begin{tabular}{|c|c|c|c|c|c|}
\hline \multirow{2}{*}{$\begin{array}{c}\text { Time } \\
\text { Group/Volume }\end{array}$} & \multicolumn{2}{|c|}{$20 \mathrm{~s}$} & \multicolumn{2}{|c|}{$300 \mathrm{~s}$} & \multirow[b]{2}{*}{ Young's modulus } \\
\hline & $12 \mathrm{~mm}^{3}$ & $24 \mathrm{~mm}^{3}$ & $12 \mathrm{~mm}^{3}$ & $24 \mathrm{~mm}^{3}$ & \\
\hline ADM & $0.208(0.02)^{\mathrm{ADa}}$ & $0.233(0.017)^{\mathrm{Aa}}$ & $0.426(0.026)^{\mathrm{BCa}}$ & $0.508(0.034)^{A B b}$ & $10.26(1.38)^{\mathrm{BE}}$ \\
\hline FBP & $0.229(0.029)^{\mathrm{ABa}}$ & $0.288(0.025)^{\mathrm{ABa}}$ & $0.433(0.035)^{\mathrm{BCa}}$ & $0.493(0.4)^{\mathrm{ABa}}$ & $17.2(1.08)^{\mathrm{D}}$ \\
\hline FBF & $0.283(0.019)^{\mathrm{BCa}}$ & $0.432(0.027)^{\mathrm{Db}}$ & $0.527(0.036)^{\mathrm{Da}}$ & $0.725(0.054)^{\mathrm{Db}}$ & $7.98(0.32)^{A}$ \\
\hline SDR & $0.199(0.015)^{\mathrm{Aa}}$ & $0.248(0.023)^{\mathrm{ABa}}$ & $0.386(0.021)^{\mathrm{ABa}}$ & $0.453(0.037)^{\mathrm{Aa}}$ & $8.62(0.45)^{\mathrm{AB}}$ \\
\hline TBF & $0.171(0.021)^{\mathrm{Aa}}$ & $0.316(0.027)^{\mathrm{BCb}}$ & $0.328(0.033)^{\mathrm{Aa}}$ & $0.548(0.023)^{\mathrm{BCb}}$ & $12.39(1)^{\mathrm{C}}$ \\
\hline XB & $0.315(0.015)^{\mathrm{Ca}}$ & $0.515(0.033)^{\mathrm{Eb}}$ & $0.525(0.021)^{\mathrm{Da}}$ & $0.77(0.052)^{\mathrm{DEb}}$ & $10.83(0.68)^{\mathrm{CE}}$ \\
\hline$X F$ & $0.214(0.019)^{\mathrm{ABa}}$ & $0.356(0.04)^{\mathrm{Cb}}$ & $0.384(0.028)^{\mathrm{ABa}}$ & $0.601(0.04)^{\mathrm{cb}}$ & $21.6(1.38)^{F}$ \\
\hline $\mathrm{Z3F}^{*}$ & $0.535(0.028)^{\mathrm{Ea}}$ & $0.788(0.066)^{\mathrm{Fb}}$ & $0.880(0.041)^{\mathrm{Ea}}$ & $1.116(0.034)^{\mathrm{Fb}}$ & $8.3(0.98)^{A}$ \\
\hline $\mathrm{Z} 3 \mathrm{XT}^{*}$ & $0.272(0.019)^{\mathrm{BCDa}}$ & $0.524(0.021)^{\mathrm{Eb}}$ & $0.473(0.018)^{\mathrm{CDa}}$ & $0.831(0.036)^{\mathrm{Eb}}$ & $17.77(1.69)^{\mathrm{D}}$ \\
\hline
\end{tabular}

${ }^{*}$ Conventional (non-bulk-fill) composites

Upper case letters mean statistically significant differences between rows in the same column (inter-groups), $\mathrm{p} \leq 0.05$

Lower case letters mean statistically significant difference between columns (intra-group) within the same row, regarding the different evaluated times (20 s - $12 \mathrm{~mm}^{3}$ versus $24 \mathrm{~mm}^{3}$; and $300 \mathrm{~s}-12 \mathrm{~mm}^{3}$ versus $24 \mathrm{~mm}^{3}$ ), p $\leq 0.05$ 
Polymerization Shrinkage Stress (in MPa)

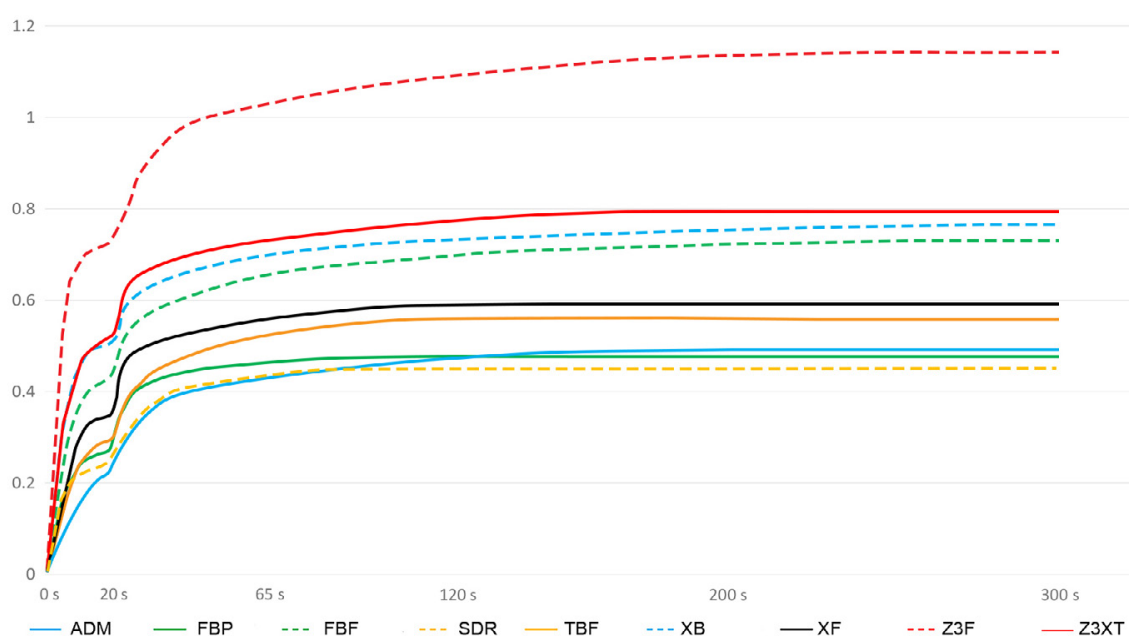

Figure 3- Stress development (in MPa) among the different composites $\left(24 \mathrm{~mm}^{3}\right)$

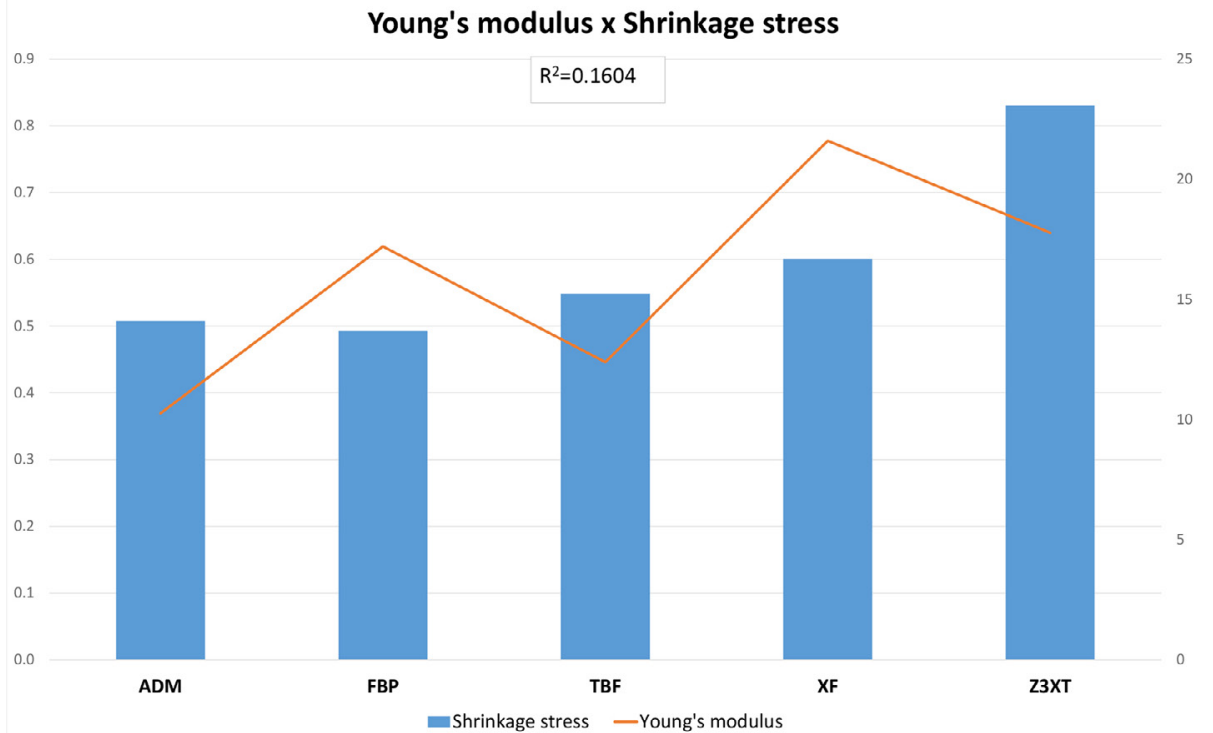

Figure 4- Young's modulus (GPa) x Shrinkage Stress (Mpa) for high-viscosity composites

lowest values, followed by some high-viscosity bulkfill composites (ADM and TBF). It is important to note that ADM and TBF presented statistically similar values to XB. The high-viscosity composites FBP, Z3XT, and $\mathrm{XF}$ presented the highest elastic modulus among the evaluated composites.

Considering the linear regression between Young's modulus and filler content, a lack of correlation for high-viscosity composites $\left(R^{2}=0.0636\right)$ and a strong correlation for low-viscosity composites $\left(R^{2}=0.9756\right)$ was observed. Another linear regression analysis was performed considering Young's modulus and shrinkage stress (Figures 4 and 5), and no correlation was observed for any of the composite groups.

\section{Discussion}

Polymerization stress generated by the inherent shrinkage of composites during light curing has been the subject of several researches for a long time, 5,28 since stress values that exceed adhesive resistance can lead to the formation of gaps in the interface. ${ }^{5,29,30}$ Therefore, the ideal composite should generate the lowest shrinkage stress possible while ensuring a better seal. ${ }^{31}$

To allow the insertion of larger increments, the molecular basis of bulk-fill composites was modified by the incorporation of stress relievers and monomers with higher molecular weight (low molecular weight monomers promote a higher number of double bonds per unit of weight, allowing a higher degree 


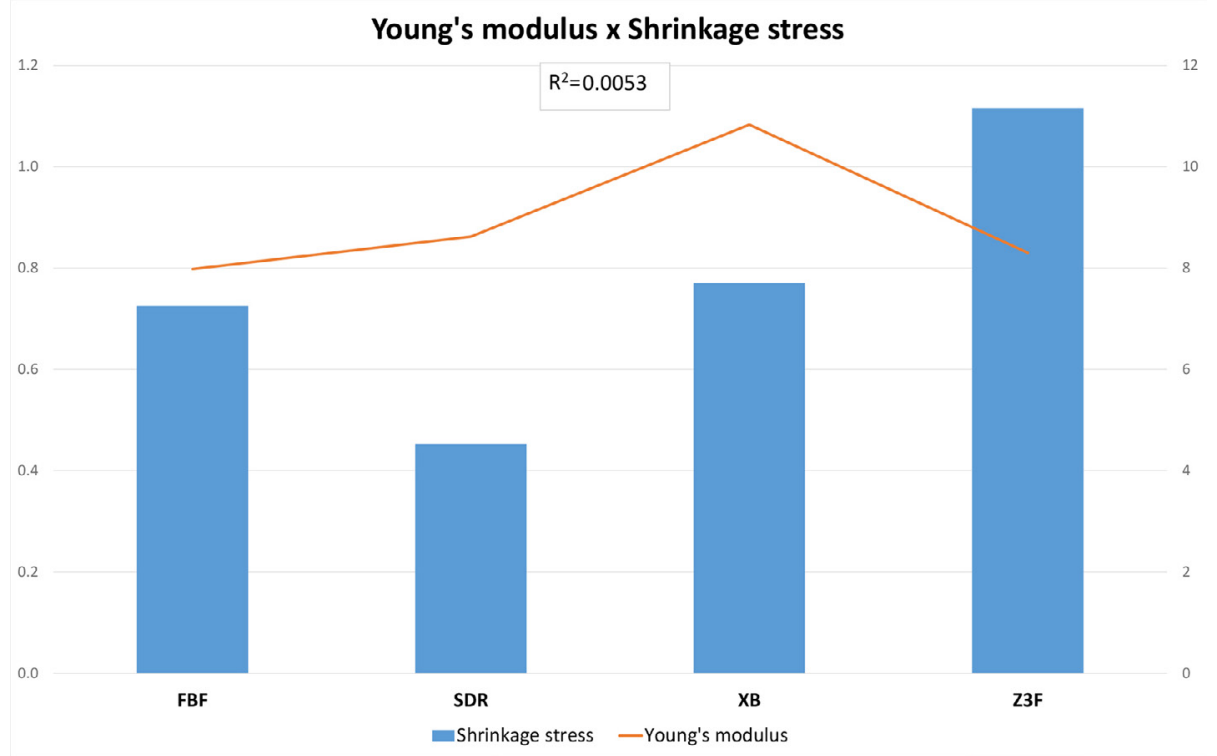

Figure 5- Young's modulus (GPa) $x$ Shrinkage Stress (MPa) for low-viscosity composites

of conversion, but also leading to higher shrinkage and shrinkage stress)..$^{5,16,18,20-23}$ One may question the organic and inorganic matrixes of these composites since "conventional" and bulk-fill composites sometimes share similar composition. Nevertheless, manufacturers usually do not report the proportion between the different monomers, neither the filler content or their proprietary formulations. ${ }^{16,20,22,28}$

Similarly, differences in filler content (e.g., when comparing high- and low-viscosity composites) may be critical in volumetric shrinkage (higher stress due to a higher amount of organic content and lower filler content is expected in low-viscosity composites). Nevertheless, a lower Young's modulus may allow stress dissipation during the polymerization process, thus reducing the stress in bigger increments. ${ }^{10,25,26,32,33}$

Considering high-viscosity composites with $12 \mathrm{~mm}^{3}$ of material after $300 \mathrm{~s}, \mathrm{TBF}$ and XF generated lower stress values when compared to the control group (Z3XT). The other bulk-fill composites presented values similar to $Z 3 X T$, but also similar to TBF and XF (Table 1). For low-viscosity/flowable composites, SDR generated the lowest stress values, followed by FBF and XB. The low-viscosity control group (Z3F) generated the highest shrinkage stress.

In general, high-viscosity bulk-fill composites generated lower shrinkage than low-viscosity bulk-fill composites as stated by other authors. 5,8,32 The only exception was SDR, which generated similar stress when compared to high-viscosity bulk-fill composites despite being flowable. Such results can be explained by the presence of a modified UDMA (monomer with high molecular weight $-849 \mathrm{~g} / \mathrm{mol}$ ) which was stated to reduce shrinkage and, consequently, shrinkage stress. ${ }^{34}$ It is interesting to note that all bulk-fill composites (high- and low- viscosity) generated similar or lower stress values when compared to the high-viscosity control (Z3XT).

Given that stress depends on the composite volume, ${ }^{29}$ testing how the volume changes the impacts caused on shrinkage stress is important. ${ }^{35}$ Increased volume $\left(24 \mathrm{~mm}^{3}\right)$ resulted in increased stress for the evaluated composites. All bulk-fill composites with $24 \mathrm{~mm}^{3}$ generated lower or similar (XB) shrinkage stress when compared to Z3XT after $300 \mathrm{~s}$ (Table 1). SDR, FBP and ADM generated the lowest stress while Z3F generated the highest stress among all tested composites.

In addition, after 300 s, SDR, FBP and ADM with $24 \mathrm{~mm}^{3}$, showed values similar to Z3XT with $12 \mathrm{~mm}^{3}$, and FBP and SDR generated similar values for both 12 and $24 \mathrm{~mm}^{3}$ (Table 1 ). Such results demonstrate a great capability of bulk-fill composites in dealing with the generation of shrinkage stress, even in big increments, as previously reported.22,36

FBP relies on monomers with higher molecular weight (AUDMA, UDMA and 1, 12-dodecane-DMA), associated with a relatively higher filler content (76.5\%) when compared to low-viscosity composites, to reduce polymerization shrinkage. The effect of monomers with higher molecular weight can be also observed in FBF, which substituted TEGDMA (286 g/ mol) for UDMA and, despite presenting the same filler content as Z3F ( $65 \%$ in weight), generated lower 
stress values. The same was observed for Xtra Base since the association between UDMA and increased filler content $(75 \%)$ contributed for a lower shrinkage stress when compared to the conventional flowable composite.

Considering ADM, it relies on a new organic matrix (Ormocer), which seems to be more flexible (as observed in Young's modulus test), even with higher filler content ( $84 \%$ according to the manufacturer), probably resulting in a material with lower polymerization shrinkage and shrinkage stress.

It is important to note how the increase in volume affected the different classes of composites. Z3XT showed the biggest proportional increase in shrinkage stress. Considering high-viscosity bulk-fill composites, the lower volumetric shrinkage might have prevented a bigger increase in stress generation. In addition to showing stress values comparable with other bulkfill composites, XF and TBF showed a big increase in stress. For XF, the higher filler content ( $86 \%$ in weight) probably reduces the polymerization shrinkage, resulting in stress values similar to other bulk-fill composites. Nevertheless, the higher Young's modulus $(21.6 \pm 1.38 \mathrm{GPa})$ (Table 1$)$, also reported in the literature, ${ }^{37}$ might have impacted the polymerization stress for XF (24 $\left.\mathrm{mm}^{3}\right)$ due to a sooner development of the composite viscosity during light curing, leading to a faster stress development when compared to some other high-viscosity bulk-fill composites (Table 1 and Figure 3). For TBF, the incorporation of $24 \%$ prepolymerized fillers increased the amount of filler content $(80 \%)$, but it still might not be capable of reducing polymerization shrinkage. Regardless, the relatively high filler content - when compared to lowviscosity composites - combined to the inclusion of a monomer with lower viscosity and higher molecular weight (UDMA), resulted in a more flexible polymer (as observed in Young's modulus test) and reduced stress.

Young's modulus can contribute to a better stress distribution when the volumetric shrinkages of composites are similar. It can be noted that all tested flowable composites showed similar Young's modulus. The lower Young's modulus for flowable composites may explain why they showed slightly better stress distribution after the increase in the increment volume when compared to Z3XT (Table 1). The higher Young's modulus in high-viscosity bulk-fill composites can be compensated with a lower polymerization shrinkage, helping to lower stress generation as observed in this study. Interestingly, ADM (10.26 $1.38 \mathrm{GPa})$ and TBF $(12.39 \pm 1.00 \mathrm{GPa})$ presented lower Young's modulus when compared to other high-viscosity composites. For ADM, the ORMOCER-based organic matrix is responsible for a more flexible polymer, despite the high filler content. For TBF, the incorporation of $24 \%$ prepolymerized fillers increases the filler content without increasing the elastic modulus, as observed by other authors. ${ }^{37,38}$

Considering shrinkage stress development, a rapid increase during the first $10 \mathrm{~s}$ of light curing (20 s total) can be observed, followed by a slower increase until the LED light is turned off. The fast subsequent cooling of the composite might be responsible for a second shrinkage peak, as reported by other authors. $22,34,39$ Shrinkage stress development seems to be slower in bulk-fill composites when compared to conventional resins. This can be observed in Figure 3, in which stress development in bulk-fill composites took longer when compared to their regular counterparts. This is especially true when comparing bulk-fill composites within the same viscosity classification (i.e., high-viscosity bulk-fill composites with lower elastic modulus: ADM and TBF, showed slower stress development). This is important because a slower stress generation allows a better stress distribution and may contribute to the bonding integrity, since the material has more time to accommodate the shrinkage stress before the elastic modulus (composite stiffness) starts to increase. ${ }^{40}$

In addition, the stress curve is flat for all composites after $200 \mathrm{~s}$, showing that most of the shrinkage develops during the initial minutes. This explains the current option for assessing shrinkage stress up to 5 minutes instead of several hours, as also observed by other authors. ${ }^{7,32,39}$

The authors of this study performed correlation tests between the elastic modulus and filler content. No correlation was observed for high-viscosity composites, but a strong correlation was observed for low-viscosity resins as reported by other authors. ${ }^{39,40}$ The low correlation between high-viscosity composites may have occurred because ADM and TBF present a relatively lower elastic modulus when compared to their filler content, as previously discussed.

In addition, no correlation was observed between shrinkage stress and elastic modulus for any of the composite groups (Figures 4 and 5). These results corroborate other authors. ${ }^{34}$ This can be explained by 
the high volumetric shrinkage of Z3XT and the use of monomers with higher molecular weight in FBP. Such results demonstrate the fundamental role of volumetric shrinkage on the generation of shrinkage stress. ${ }^{34,40}$ This statement supports the results of this study, since all flowable composites (with lower filler content) are expected to present higher shrinkage and generate higher shrinkage stress. ${ }^{32}$ The SDR group is an outlier as already discussed and as previously reported. ${ }^{34}$

Although having benefits that may reflect in easier and faster cavity restorations, bulk-fill composites still require further studies to assess the influence of their properties on the long-term maintenance of internal and marginal adaptation. Assessing the interaction between bulk-fill composites and tooth structure regarding adaptation, cusp deflection, among other factors, will also be important.

These results show, in general, a better behavior for bulk-fill composites regarding the generation of shrinkage stresses, mainly when larger increments are used. Nevertheless, it is important to note that despite being classified as bulk-fill resin composites, the different tested materials can show very different behavior, not only regarding the different classifications (low- and high-viscosity) as would be expected. Further tests are advised to clarify the best indication for each composite to clinicians. In addition, bulk-fill composites and regular composites also showed very different properties as previously discussed and, thus, the initial hypothesis was accepted.

\section{Conclusion}

Considering the limitations of this study, it was possible to conclude that bulk-fill composites present very heterogeneous behavior, which is related to their composition (monomers and filler content).

In addition, it can be concluded that:

Bulk-fill resin composites present equal to lower shrinkage stress generation when compared to conventional composites, mainly with bigger increments.

Bulk-fill composites show a wide range of elastic young's modulus values, but usually similar to "regular" composites.

Volumetric shrinkage seems to be more important than elastic modulus for polymerization stress development.

\section{Acknowledgements}

This study was partially funded by the Coordination of Higher Education and Graduate Training (CAPES), Brazil. The authors would like to thank all the manufacturers for the donation of the composites used in this study.

The authors would like also to thank Dr. José Roberto Pereira Lauris from the Department of Pediatric Dentistry, Orthodontics and Community Health, Bauru School of Dentistry, University of São Paulo, for his assistance in the statistical analysis of this study.

\section{References}

1- Araujo FO, Vieira LC, Monteiro Junior S. Influence of resin composite shade and location of the gingival margin on the microleakage of posterior restorations. Oper Dent. 2006;31(5):556-61.

2- Dhingra V, Taneja S, Kumar M, Kumari M. Influence of fiber inserts, type of composite, and gingival margin location on the microleakage in Class II resin composite restorations. Oper Dent. 2014;39(1):E9-15. 3- Peutzfeldt A, Muhlebach S, Lussi A, Flury S. Marginal gap formation in approximal "bulk fill" resin composite restorations after artificial ageing. Oper Dent. 2018;43(2):180-9.

4- Veloso SR, Lemos CA, Moraes SL, Egito Vasconcelos BC, Pellizzer EP, Melo Monteiro GQ. Clinical performance of bulk-fill and conventional resin composite restorations in posterior teeth: a systematic review and meta-analysis. Clin Oral Investig. 2018. doi: 10.1007/s00784018-2429-7. Epub ahead of print.

5- Kruly PC, Giannini M, Pascotto RC, Tokubo LM, Suga US, Marques $A C$, et al. Meta-analysis of the clinical behavior of posterior direct resin restorations: low polymerization shrinkage resin in comparison to methacrylate composite resin. PLoS One. 2018;13(2):e0191942. $6-\mathrm{Kim} \mathrm{HJ}$, Park $\mathrm{SH}$. Measurement of the internal adaptation of resin composites using micro-CT and its correlation with polymerization shrinkage. Oper Dent. 2014;39(2):E57-70.

7- Ishikiriama SK, Maenosono RM, Oda DF, Ordóñez-Aguilera JF, Wang $L$, Mondelli RF. Influence of volume and activation mode on polymerization shrinkage forces of resin cements. Braz Dent J. 2013;24(4):326-9.

8- Tauböck TT, Jäger F, Attin T. Polymerization shrinkage and shrinkage force kinetics of high- and low-viscosity dimethacrylate- and ormocerbased bulk-fill resin composites. Odontology. 2018. doi: 10.1007/ s10266-018-0369-y. Epub ahead of print.

9- Oliveira LR, Braga SS, Bicalho AA, Ribeiro MT, Price RB, Soares $C]$. Molar cusp deformation evaluated by micro-CT and enamel crack formation to compare incremental and bulk-filling techniques. J Dent. 2018;74:71-8.

10- Gonçalves F, Campos LM, Rodrigues-Júnior EC, Costa FV, Marques $\mathrm{PA}$, Francci $\mathrm{CE}$, et al. A comparative study of bulk-fill composites: degree of conversion, post-gel shrinkage and cytotoxicity. Braz Oral Res. 2018;32:e17.

11- Ferracane JL, Hilton TJ. Polymerization stress - is it clinically meaningful? Dent Mater. 2016;32(1):1-10.

12- Krämer N, García-Godoy F, Reinelt C, Feilzer AJ, Frankenberger R. Nanohybrid vs. fine hybrid composite in extended Class II cavities after six years. Dent Mater. 2011;27(5):455-64. 
13- Van Dijken JW, Pallesen U. Clinical performance of a hybrid resin composite with and without an intermediate layer of flowable resin composite: a 7-year evaluation. Dent Mater. 2011;27(2):150-6.

14- Dietschi D, Monasevic M, Krejci I, Davidson C. Marginal and internal adaptation of class II restorations after immediate or delayed composite placement. J Dent. 2002;30(5-6):259-69.

15- Campos EA, Ardu S, Lefever D, Jassé FF, Bortolotto T, Krejci I. Marginal adaptation of class II cavities restored with bulk-fill composites. J Dent. 2014;42(5):575-81.

16- Ilie $N$, Hickel R. Investigations on a methacrylate-based flowable composite based on the SDR ${ }^{\mathrm{TM}}$ technology. Dent Mater. $2011 ; 27(4): 348-55$.

17- Moorthy A, Hogg CH, Dowling AH, Grufferty BF, Benetti AR, Fleming GJ. Cuspal deflection and microleakage in premolar teeth restored with bulk-fill flowable resin-based composite base materials. J Dent. 2012;40(6):500-5.

18- Meereis CT, Münchow EA, Oliveira da Rosa WL, Silva AF, Piva E. Polymerization shrinkage stress of resin-based dental materials: a systematic review and meta-analyses of composition strategies. J Mech Behav Biomed Mater. 2018;82:268-81.

19- Garcia D, Yaman P, Dennison J, Neiva G. Polymerization shrinkage and depth of cure of bulk fill flowable composite resins. Oper Dent. 2014;39(4):441-8.

20- Burgess J, Cakir D. Comparative properties of low-shrinkage composite resins. Compend Contin Educ Dent. 2010;31:10-5.

21- Czasch $\mathrm{P}$, Ilie N. In vitro comparison of mechanical properties and degree of cure of bulk fill composites. Clin Oral Investig. 2013;17(1):227-35.

22- Kim RJ, Kim YJ, Choi NS, Lee IB. Polymerization shrinkage, modulus, and shrinkage stress related to tooth-restoration interfacial debonding in bulk-fill composites. J Dent. 2015;43(4):430-9.

23- Jang JH, Park SH, Hwang IN. Polymerization shrinkage and depth of cure of bulk-fill resin composites and highly filled flowable resin. Oper Dent. 2015;40(2):172-80.

24- Correa MB, Henn S, Marimon JL, Rodrigues SA Jr, Demarco FF. Factors influencing the microhardness of a microhybrid composite. Gen Dent. 2010;58(2):e94-8.

25- Fronza BM, Rueggeberg FA, Braga RR, Mogilevych B, Soares LE, Martin AA, et al. Monomer conversion, microhardness, internal marginal adaptation, and shrinkage stress of bulk-fill resin composites. Dent Mater. 2015;31(12):1542-51.

26- Ferracane JL. Resin-based composite performance: are there some things we can't predict? Dent Mater. 2013;29(1):51-8.

27- Ishikiriama SK, Valeretto TM, Franco EB, Mondelli RF. The influence of "C-factor" and light activation technique on polymerization contraction forces of resin composite. J Appl Oral Sci. 2012;20(6):6036.
28- El-Damanhoury $\mathrm{H}$, Platt J. Polymerization shrinkage stress kinetics and related properties of bulk-fill resin composites. Oper Dent. 2014;39(4):374-82

29- Dejak B, Mlotkowski A. A comparison of stresses in molar teeth restored with inlays and direct restorations, including polymerization shrinkage of composite resin and tooth loading during mastication. Dent Mater. 2015;31(3):77-87.

30- Hayashi J, Shimada Y, Tagami J, Sumi Y, Sadr A. Real-time imaging of gap progress during and after composite polymerization. J Dent Res. 2017;96(9):992-8.

31- Han SH, Sadr A, Tagami J, Park SH. Internal adaptation of resin composites at two configurations: influence of polymerization shrinkage and stress. Dent Mater. 2016;32(9):1085-94.

32- Jung JH, Park SH. Comparison of polymerization shrinkage, physical properties, and marginal adaptation of flowable and restorative bulk fill resin-based composites. Oper Dent. 2017;42(4):375-86.

33- Prager M, Pierce M, Atria PJ, Sampaio C, Cáceres E, Wolff M, et al. Assessment of cuspal deflection and volumetric shrinkage of different bulk fill composites using non-contact phase microscopy and microcomputed tomography. Dent Mater J. 2018;37(3):393-9.

34- Kim YJ, Kim R, Ferracane JL, Lee IB. Influence of the compliance and layering method on the wall deflection of simulated cavities in bulk-fill composite restoration. Oper Dent. 2016;41(6):e183-94.

35- Aregawi WA, Fok AS. $1 /(2+R c)$ : a simple predictive formula for laboratory shrinkage-stress measurement. Dent Mater. 2017;33(5):536-42.

36- Rosatto CM, Bicalho AA, Veríssimo C, Braganca GF, Rodrigues MP, Tantbirojn D, et al. Mechanical properties, shrinkage stress, cuspal strain and fracture resistance of molars restored with bulk-fill composites and incremental filling technique. J Dent. 2015;43(12):1519-28.

37- Leprince JG, Palin WM, Vanacker J, Sabbagh J, Devaux J, Leloup G. Physico-mechanical characteristics of commercially available bulk-fill composites. J Dent. 2014;42(8):993-1000.

38- Ilie N, Bauer H, Draenert M, Hickel R. Resin-based composite light-cured properties assessed by laboratory standards and simulated clinical conditions. Oper Dent. 2013;38(2):159-67.

39- Kalliecharan D, Germscheid W, Price RB, Stansbury J, Labrie D. Shrinkage stress kinetics of bulk fill resin-based composites at tooth temperature and long time. Dent Mater. 2016;32(11):1322-31.

40- Al Sunbul H, Silikas N, Watts DC. Polymerization shrinkage kinetics and shrinkage-stress in dental resin-composites. Dent Mater. 2016;32(8):998-1006. 